\section{Aero Engines of the 1920s}

I REFER to Wing Cdr. Macmillan's letter in the November JouRNAL. The operations of Rolls-Royce between 1921, when Rowledge joined the Company, and the production of the Kestrel have never received much publicity. A disclosure of the facts relating to this period call for a modification of the statement that "no one at the Air Ministry and certainly no one in industry made a move to low frontal area until after confrontation by the Curtiss D 12" in Fairey Aircraft. While these remarks may have been true of the aircraft builders, Rowledge at Rolls-Royce had seen the light in 1921, hence his treatment of the Condor. He shortened the connecting rods to reduce the cylinder height and fitted a spur reduction gear in place of the original epicyclic so as to bring the propeller shaft as nearly as possible in the centre of the front view of the engine. These breaks with traditional Rolls-Royce design were carried straight through to the Kestrel design and retained for the same reasons they were introduced on the Condor-to reduce frontal area and improve the fairing behind the spinner. The aircraft designers took no advantage of these new design features on the Condor, as witness the Horsley and other contemporary Condor installations. It must be remembered that in the early twenties, engine builders had little say in how their engines were mounted, let alone how they were installed or cooled. The Condor was too large for the fighter requirements of the day and therefore missed the most important market.

After the Condor and before the Kestrel, Rolls-Royce designed and tested prototypes of two engines both of which were intended to meet the demand for low-drag installations.

The first of these was a swash-plate engine employing Michel thrust pads to transmit the gas pressure on the piston to the inclined disc. This engine was probably' the best shape for installation which could be devised. The arrangement also promised to overcome the difficulties with white metal big end bearings which gave much trouble at that time. The second engine was a 16 cylinder, four row, four throw crank $\mathrm{X}$ formation, designed to provide an engine of minimum length and minimum frontal area.

Both these engines were built under contract to the Air Ministry who covered all the development costs. Work on them was stopped by Royce so that there might be complete concentration at Derby on the Kestrel, the demand for which already existed.

The prototype swash plate engine was later transferred to Napiers, at their request, but what happened to it thereafter I do not know.

Low drag form and better cooling than that obtainabie from the more popular air cooled radials of those days, were the only advantages which the water cooled engine had to offer. This fact was most certainly appreciated by Rolls-Royce engineers in 1921.

\section{2nd November 1966. RUDSTON Fell, Fellow}

While agreeing with Col. Fell's statements and appreciating some experimentation was always proceeding, no important change in British liquid-cooled aero engine configuration became available until Fairey introduced the D12. The Condor I flew in 1925 still had separate cylinders and a large frontal area relative to its bhp. But after an Air Ministry D12 (imported by Fairey) was sent to Derby for examination as the kind of engine the Air Ministry wanted, Rolls-Royce's first monobloc V12 aero engine, the F11 with greatly reduced frontal area, which first flew in August 1927, ended a long period of stagnation.

\section{The Wyvenhoe Fller}

THE mention of the "Wyvenhoe Flier" in the review of Mr. G. R. Duval's excellent book, British Flying Boats and Amphibians 1909-1952 (p 962, October) prompts me to write and tell you that several years ago I gave myself the pleasure of doing a certain amount of research into the aeronautical activities of its creator, Mr. J. E. Humphreys. Humphreys was one of the many destined to play only a small part in the story of the aeroplane in those vital years immediately preceding the First World War and one has to admit that his work generally was of no great historical significance. Nevertheless I am very glad that I did investigate further, since it turned out to be an intriguing exercise for its own sake and the interest it provided for me amply repaid my efforts.

During the course of this research I met Mr. Humphreys who, although already elderly, was still practising his profession of dental surgery. While talking to him I formed the impression that he had done some pretty advanced thinking in his time, as he told me of tentative experiments with modified commercial compressors, experiments which seemed to me to be groping towards the ducted fan. He also apparently had some ideas on direct iift using a compressor, but I gather these never got beyond the thinking stage.

Actually the Wyvenhoe Flier (one of the world's earliest attempts at a flying-boat) was only the first of his three machines, the other two being monoplanes with land undercarriages. The first of these with bird-shaped wings was in fact entered for the $£ 1000$ competition for the first circular mile. A valiant attempt was made but it was foredoomed to failure since the machine had not even proved itself capable of flight! As far as I have been able to ascertain this aircraft never did become airborne. The final monoplane, however, was a very advanced design for this country at the time (1910) and although I would say it owed more than a little to the Antoinette concept, it is nevertheless a pity that financial considerations forced $\mathrm{Mr}$. Humphreys to abandon it sometime in 1911-12, but not until it had shown itself capable of flight at Brooklands in somewhat spectacular fashion in the hands of GordonBell, with two passengers riding on the leading edge of the wings on either side of the $60 \mathrm{hp}$ Green engine!

Thanks to a vigilant friend, I have been able to recover from a shipyard at Rowhedge (close to where Humphreys' machines were built) portions of the hull of the "Flier" and some of the wing structure and propeller of the first monoplane. I am exceedingly glad to have these relics since they constitute a mute tribute to the skill and craftsmanship of the shipwrights and fitters who, without ever having seen anything remotely resembling an aircraft, nevertheless managed to turn out a remarkably "aeroplane-like" structure. The wing construction, for instance, is quite astonishingly sophisticated for this country and time (1909), being comparatively thick with spindled "I" section spars and warren truss ribs, the members of which are all chamfered to triangular section between joints. The propeller is based on the Voisin design and is probably the first of its type made in this country-it certainly reflects great credit on some blacksmith or metal-worker of an almost forgotten age.

22nd October $1966 . \quad$ M. P. SAYER, Associate 